\title{
Botànica i llengua. Fitonímia, etimologia i motivació lèxica
}

\author{
Joan Veny \\ Institut d'Estudis Catalans - Universitat de Barcelona \\ jveny@iec.cat
}

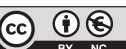

Rebut: juny de 2015

Acceptat: gener de 2016

\section{Resum}

Partint de dues fonts, els Noms de plantes. Corpus de fitonímia catalana (TERMCAT) i l'Atles Lingüístic del Domini Català (UB i IEC) es fa veure la utilitat complementària d'una i altra, es fa la distinció entre etimologia i motivació, s'examina la introducció de manlleus en català, s'esbossa una classificació lexicogenètica i s'exemplifica la renovació del lèxic a través de l'homonímia i l'etimologia popular. Es proposen dues noves etimologies (jovenal i panigroc), s'illustren amb nous exemples models lèxics sintagmàtics i es dóna compte de la prioritat que es dóna als fitònims introduïts al Diccionari de la llengua catalana (1995 i 2007) de l'Institut d'Estudis Catalans.

Paraules clau: llengua catalana; història de la llengua; fitonímia; etimologia; motivació lèxica; lexicografia; llengua estàndard.

Resumen. Botánica y lengua. Fitonimia, etimología y motivación léxica

Partiendo de dos fuentes, Noms de plantes. Corpus de fitonímia catalana (TERMCAT) y Atles Lingüístic del Domini Català (UB y IEC) se da cuenta de la utilidad complementaria de una y otra, se establece la distinción entre etimología y motivación, se examina la introducción de préstamos en catalán, se esboza una clasificación léxico-genética y se ejemplifica la renovación del léxico a través de la homonimia y la etimología popular. Se proponen dos nuevas etimologías (jovenal y panigroc), se ilustran con nuevos ejemplos modelos léxicos sintagmáticos y se establece la prioridad que se otorga a los fitónimos introducidos en el Diccionari de la llengua catalana (1995 y 2007) del Institut d'Estudis Catalans.

Palabras clave: lengua catalana; historia de la lengua; fitonimia; etimología; motivación léxica; lexicografía; lengua estándar.

Abstract. Botany and language. Phytonomy, etymology and lexical motivation

Based on two sources, Noms de plantes. Corpus de fitonímia catalana (TERMCAT) and Atles Lingüístic del Domini Català (UB and IEC), this article aims to show the complementary utility of both sources, to make the distinction between etymology and motivation, to study the introduction of Catalan loanwords, to make a lexical-genetic classification and to exemplify the lexical renovations using the homonomy and the popular etymology. Two new etymologies are suggested (jovenal and panigroc), lexical-syntagmatic models are illustrated with new examples and it is shown the priority that is given to the phytonoms which are 
introduced to the Diccionari de la llengua catalana (1995 and 2007) by Institut d'Estudis Catalans.

Keywords: Catalan language; History of language; phytonomy; etymology; lexical motivation; lexicography; standard language.

\begin{aligned} & \multicolumn{2}{c}{ Sumari } \\ & Fitonímia diacrònica Homonímia i etimologia popular, \\ & Botànica i etimologia impulsos renovadors del lèxic \\ & Dues fonts d'estudi El repte de l'etimologia \\ & Comparació cronològica de fonts i Dues noves etimologies: jovenal \\ & restitució del nom correcte i panicrost \\ & Importància en l'ALDC, de la Estructura morfosintàctica \\ & transcripció fonètica Botànica i normativa \\ & Etimologia Botànica i poesia \\ & Motivació Conclusions \\ & Els manlleus Referències bibliogràfiques \\ & Classificació \end{aligned}

\section{Fitonímia diacrònica}

La lexicologia diacrònica s'edifica sobre tres pilars: la documentació antiga, la dialectologia — amb una branca que és la cultura popular-, i la moderna lingüística de corpus. En la nostra exposició sobre l'origen d'alguns mots de fitonímia, deixant de costat la documentació antiga, comprovarem l'eficàcia de les observacions metalingüístiques dels informadors dialectals així com de la comparació de variants corresponents a un tàxon.

\section{Botànica i etimologia}

La botànica ha acumulat, des del segle XVIII, un bon nombre de reculls de plantes amb els noms populars i l'equivalent científic. La descripció de la planta i l'al·lusió a certes apreciacions per part del poble (virtuts, maleficis, llegendes, etc.) ajuden a l'hora de fer-ne la interpretació etimològica o motivacional. Citem, entre altres, Serra (1772), Barrère (s. XVIII), Richart (1839), Vayreda (1852), Bassegaña (1859), Teixidor (1871), Costa (1877), Barceló (1879-1881), Montserrat (1880), Gibert (1892), Font i Quer (1962), Masclans (1954 [1981]). Aquests dos darrers aporten sovint referències motivacionals interessants. Per cert, Verdaguer va anotar noms de plantes d'algunes d'aquestes obres (Costa, Gibert, Teixidor) per introduir-les en la seva obra, en la qual, aquí i allà, rumbeja poèticament el vocabulari de la flora. 
Tot i que l'etimologia ha fet força progressos en els darrers decennis, la referent a la fitonímia té un camp encara pendent d'estudi. Les paraules de Coromines, escrites ara fa 60 anys, continuen tenint actualitat: "Qué poco se han estudiado los nombres de plantas, de peces y aves» (DCEC, I, p. X).

L'objectiu medul.lar d'aquest estudi és desvelar l'etimologia de dues plantes, el jovenal i el panicrost. ${ }^{1}$

\section{Dues fonts d'estudi}

Actualment, disposem de dues fonts d'estudi de gran utilitat, de les quals no disposava Coromines: Noms de plantes. Recull de fitonímia catalana (NP), del TERMCAT, i l'Atles Lingüístic del Domini Català (ALDC), de la Universitat de Barcelona i l'Institut d'Estudis Catalans.

El NP conté àrees geogràfiques i espais puntuals; quant a fonts, n'hi ha d'escrites i d'orals, publicades o no; i temàticament, conté tant reculls generals com específics (plantes medicinals, tòxiques, mel·líferes, molses, etc.).

L'ALDC recull dades en transcripció fonètica (una part de les enquestes són gravades), en tot el domini lingüístic, recollides durant un lapse de temps limitat (1964-1974), a càrrec d'un equip de lingüistes, formats en la mateixa metodologia, i servint-se d'informadors d'edat de cadascuna de les 190 poblacions enquestades. S' han tingut en compte els capítols «11. Els vegetals», del vol. V, amb 200 unitats, i, ocasionalment, els capítols «9. El camp i els cultius» i «10. Indústries relacionades amb l'agricultura», del vol. IV.

La utilitat dels dos grans projectes és complementària. NP té l'avantatge de la multiplicitat de formes elencades, quasi exhaustiva, amb el nom científic de cada planta i la font respectiva, i l'ALDC, el fet de presentar la transcripció fonètica i la seva localització geogràfica. El primer, fet per biòlegs i lingüistes, i el segon, per lingüistes.

\section{Comparació cronològica de fonts i restitució del nom correcte}

Comparant cronològicament les dades referents a un tàxon i observant-ne el referent, podem corregir una forma que havia estat modificada per mala interpretació del nucli:

Espècie 'Briza maxima'

Poltrú d'eruga (Rodríguez Femenias 1904)

Poltrú d'eruga (Masclans 1954)

*Poltre d'eruga (Masclans $1981 \rightarrow$ DIEC)

S'ha restituït el nom originari, basat en el fet que la planta «fa bolletes en forma de poltrú 'budell gros', com formant un capoll d'eruga» (Villalonga,

1. Em plau expressar la meva gratitud a José Enrique Gargallo i a Xavier Luna-Batlle, per la revisió d'aquest text, i a Montse Roma, per l'ajut informàtic. 


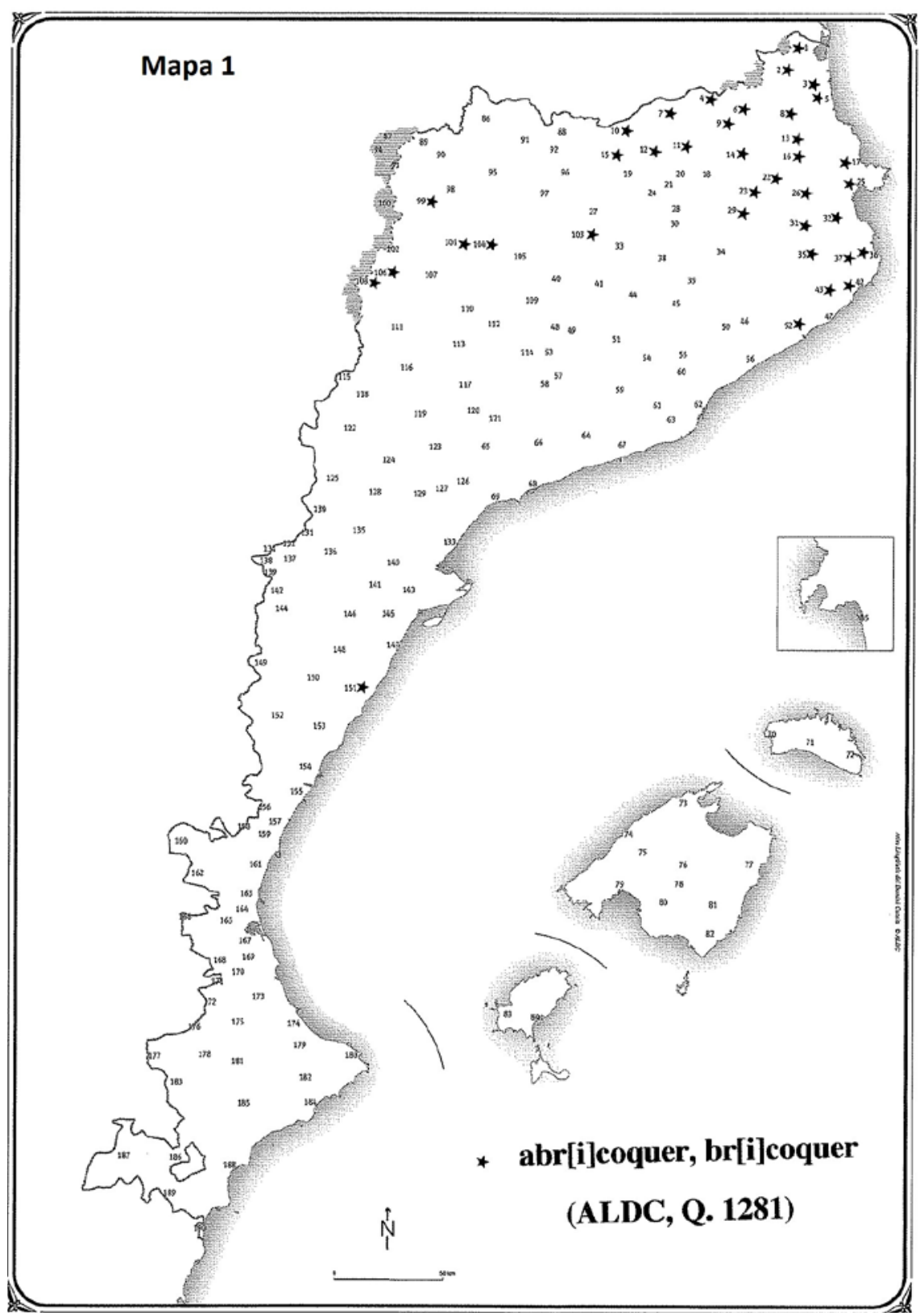

Mapa 1. Del mapa 1165 de l'Atles Lingüístic del Domini Català. 


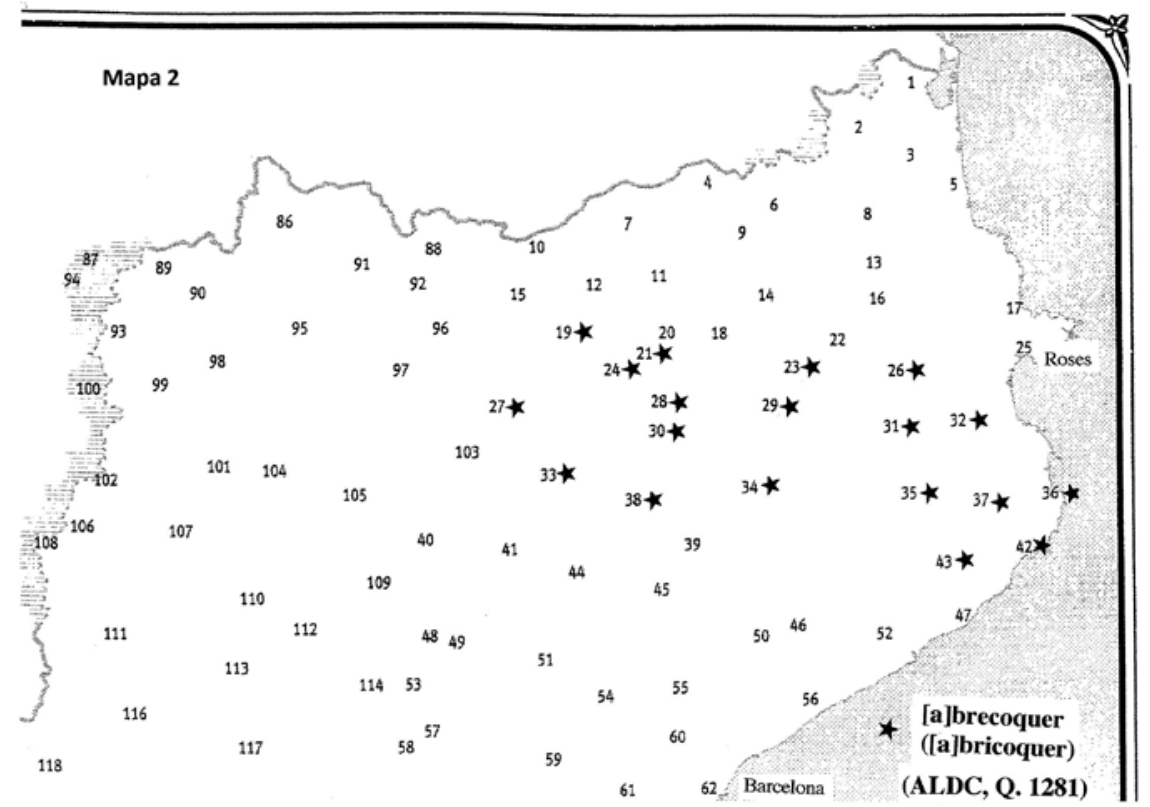

Mapa 2. Del mapa 1165 de l'Atles Lingüístic del Domini Català.

2010). Poltrú, com a nom de budell i d'embutit, coneix variants fonètiques: poltruc, paltruc, paltrot, poltruu (DCVB).

\section{Importància en l'ALDC, de la transcripció fonètica}

A través de NP, no sabem si les variants abrecoquer, abracoquer 'albercoquer', pròpies del català oriental, es pronuncien [əbrəkuk'e] o [,abrəkuk'e]: l'ALDC (V, mapa 1165) confirma aquesta darrera pronúncia, que és resultat d'una homonimització semàntica (atracció d'a[r]bre) (vegeu els mapes 1 i 2).

\section{Etimologia}

El català és una llengua romànica; el seu lèxic bàsic se sustenta en el llatí i les seves lleis fonètiques evolutives es basen en el llatí parlat: casa, jonoll, rosa, riu, vall, etc., són herència llatina; i és així com el llat. CASTANEA ha donat castanya a través de CASTANIA, per tancament de la $e$ en hiat, i per la palatalització de la $\mathrm{N}$ per la I en [n] (com PINEA > pinya, VINEA > vinya, LINEA > llinya), d'acord amb un tractament gairebé sistemàtic, regular del grup -ni- < NE. O bé TREMULus que, a més de 'tremolós', en llatí ja significava 'trèmol, Populus tremula'. Així, diem que CASTANEA és l'ètim o l'etimologia de castanya i TREMULus, de trèmol. 


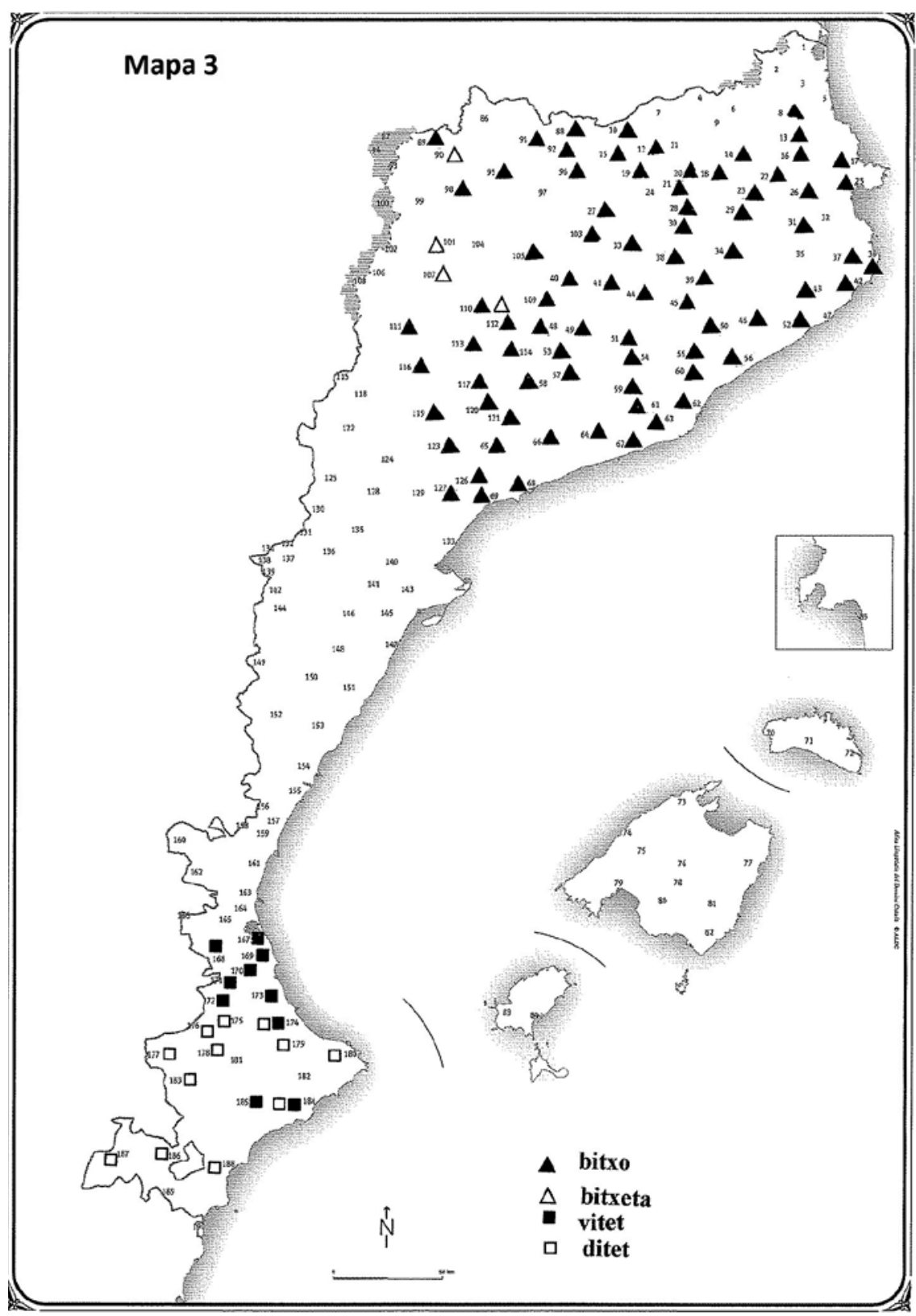

Alguns noms del 'bitxo' (ALDC, 1249)

Mapa 3. Del mapa 1134 de l'Atles Lingüístic del Domini Català. 
Però, com veurem, no es coneix l'etimologia de tots els mots: d'alguns, aquesta és desconeguda, tot i que els especialistes malden per obrir clivelles de llum dins l'obscuritat, propostes que romanen sovint en el regne del dubte o de la incertesa. I també hi ha motivacions que resten fosques, opaques.

\section{Motivació}

Hi ha un segon cas, el de la motivació, és a dir, l'adquisició de nous significats a través sobretot de la metàfora i la metonímia: per exemple, quina relació semàntica té rusc 'casera d'abelles' amb 'escorça', que és el significat de l'ètim RuscA? Simplement que els ruscos es feien de l'escorça, sobretot de l'alzina surera. O bé, tornant a castanya, quina és la motivació de castanya 'cop a la cara' o la de castany 'marró'? En el primer cas, la frequiència d'aplicar semànticament a la 'bufetada' el nom d'un fruit (pinya, nespla, carxofa, xufa, cirera, bolet, xereca 'casta de figa', etc. [ALDC, I, m. 115]); i en el segon, castany, per la metàfora del color de la pell de la castanya.

\section{Els manlleus}

Ultra això, el català, com les altres llengües romàniques, a més de tenir per base el fons hereditari llatí, s'ha enriquit amb les aportacions d'altres llengües, que constitueixen manlleus. És tasca dels diacronistes esbrinar de quina llengua provenen aquests. En el cas del català, les llengües veïnes o d'adstrat —l'occità, l'aragonès, el castellà o el sard- ens n'han fornit exemples.

L'occità, deixant a part els mots deguts a la influència literària dels trobadors —alguns poetes catalans escrivien poesia en occità—, ens ha llegat:

1) mots incorporats a la llengua general: per exemple, bitxo 'coralet, pebrina' no hauria pujat de Castelló cap al Principat, des de la pronúncia vitx, pl. de vit (DECat), sinó que hauria descendit des de l'occità on VECTE 'palanca' esdevé vièch 'membre viril' i 'noms de mariscos de motivació fàl-lica', convertit, per metàfora, en 'coralet, pebrina' (mapa 3; Veny, 2013: 498-499);

2) mots (i trets fonètics i morfosintàctics) assentats en la part septentrional del domini, el rossellonès: per exemple, espinards 'espinacs'; com que podríem pensar en el francès épinards com a mot de sortida (francès i occità són llengües gal-loromàniques), ens confirma l'origen occità la documentació del mot en rossellonès, anterior al segle XVII, quan comença la francesització de la Catalunya del Nord (Veny, 1980); igualment trauca-sacs 'cugula' (ALDC, $\mathrm{V}, 1072$ ); en canvi trefleltrèfula 'trèvol' (ALDC, V, 1069), que s'estén més al sud, podria ser expansió des del francès. A voltes, es tracta d'una evolució pròpia, com és el cas de (d)espullabelitres 'gavarrera; gavarró' (ALDC, V, 1067 i 1068) «per la coïssor insuportable que produeix a la pell si s'hi posa en contacte, i que obliga a despullar-se per gratar-se més a pler» (DCVB, s. v.). (cf. picaesquenes «perquè pica de debò a l'esquena», ALDC, loc. 69 del mapa 1067). 


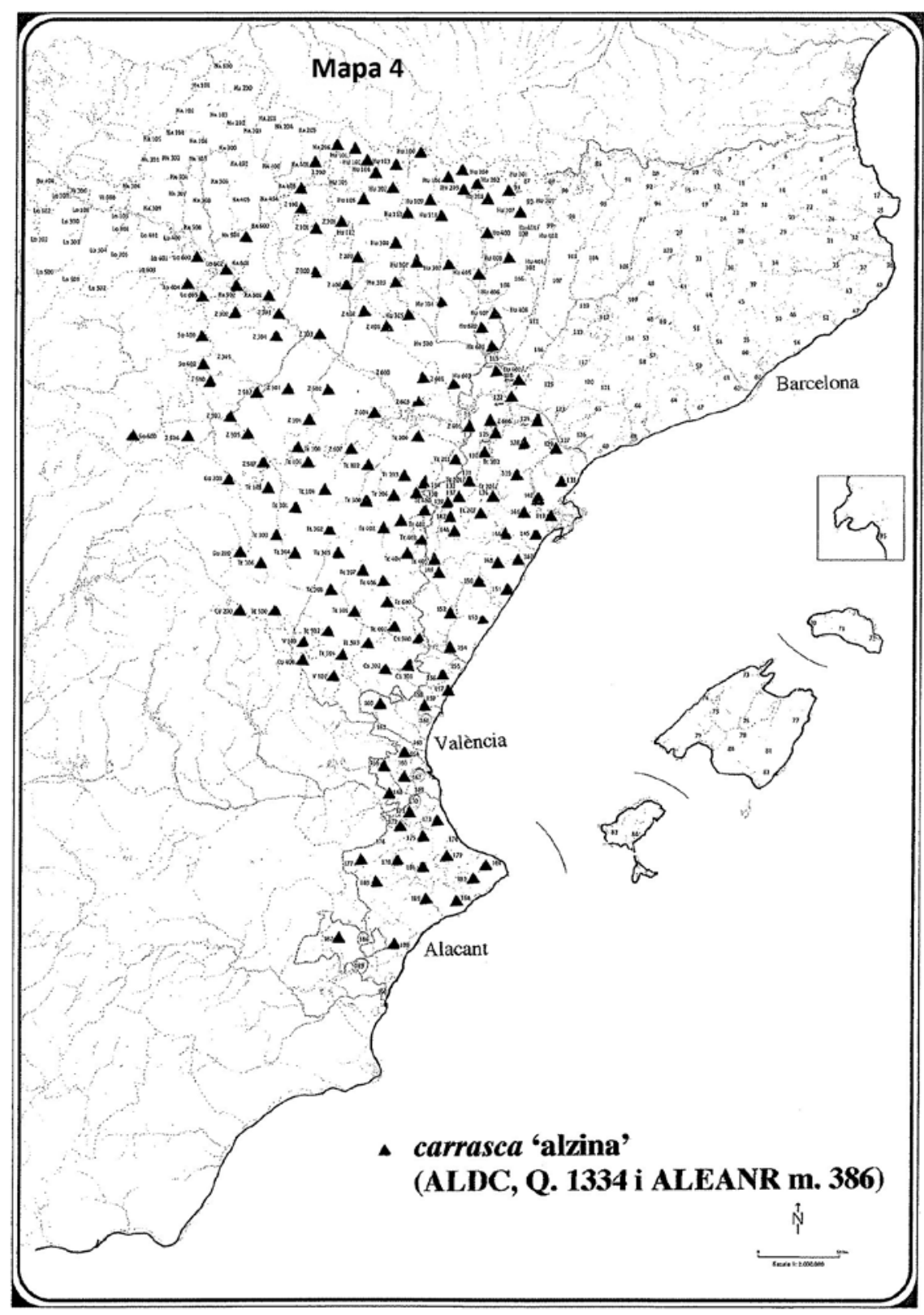

Mapa 4. Del mapa 1216 de l'Atles Lingüístic del Domini Català i del mapa 386 de l'Atlas lingüístico y etnográfico de Aragón, Navarra y Rioja. 
L'aragonès ha influït en el valencià a causa de la conquesta i colonització d'aquest territori per catalans i aragonesos. En moltes de les poblacions avui de parla catalana s'hi establiren uns i altres, s'hi imposà el català, pero l'aragonès hi deixà supervivents; per exemple, fullarasca 'fullaraca' 1251 (Veny, 2013: 502503); potser carrasca 'alzina' 1216 (mapa 4), amb documentació sobretot valenciana des del segle XIV.

El castellà, més que en qualitat d'adstrat, ha actuat sobre el català com a superstrat, resultat de la influència d'un poble dominador i no ens n'ocuparem. El valencià hi ha estat particularment sensible. Un exemple, rabo de gat, rabo de cavall 'Equisetum arvense' i altres espècies; rabo 'extremitat pilosa' enfront de coa/cua 'extremitat carnosa' (per exemple, d'un peix).

L'Alguer, on es parla català des del segle XIV, que va rebre al llarg dels segles, especialment des del segle XVI, la immigració de població sarda, ha estat objecte d'una profunda sardització, tot mantenint la seva essència bàsica catalana: criel-lei 'Chrisantemum leucanthemifolium', «entrato da tempi remoti nella sfera del culto dei morti e quindi del sacro» (< KYRIE ELEISON 'senyor, pietat', de la lletania que convida a la son) (Caria, 2001: 85). Igualment calarigue 'arç blanc, Crataegus monogyna' (< logudorès); cagaranxu 'coronària, Chrysantemum coronarium' (< logudorès cagaranzu), etc. (Caria, 2001: 54-55, 56-57).

Queden a part les llengües que ens han proporcionat manlleus a través de la cultura, la indústria, l'art, els progressos tècnics, etc., sense contacte geogràfic (el francès, l'anglès, l'italià, etc.), però amb poca —o nul·la— transcendència en el món botànic.

\section{Classificació}

Una possible classificació lexicogenètica dels noms de plantes seria així, segons la pauta inicial de Bigas-Milian (1996), sense pretensió d'exhaustivitat, amb exemples nostres que tenen tant un caràcter descriptiu (pelosella) com metafòric (conillets), o metaforicometonímic (contell):

a) segons la morfologia de la planta:

1) forma: barretets, agulles;

2) color: rogeta, blat de perdiu, figa llimonenca;

3) olor: trèvol d'olor, herba pudenta;

4) gust: herba amarganta;

5) tacte: pelosella, pèl de farigola, (figa) pèl de bou (per la pilositat); (figa) cuiro de bou (per l'aspresa);

6) mida: ortiga gran, ortiga petita;

b) segons l'hàbitat:

1) zona geogràfica de procedència: blat de les Índies, meló de moro; a voltes suposada: blat de moro; o amb referència a una espècie pròpia d'una àrea: clavell valencià;

2) medi: llentieta d'aigua o pa de granota, belluguets;

c) segons el temps de floració o de collita: herba de Sant Joan, clavellina de mort; nadala; 
d) segons l'aplicació, la virtut, la utilitat, el poder curatiu: herba berruguera, herba mosquitera, herba dels fics, adormidera.

Comentaré exemples d'algunes motivacions.

Pel que fa a la forma, la metàfora és a l'ordre del dia: el mot antic coltell o contell 'ganivet' (< CUlTELlu) s'ha aplicat a 'lliri dels blats, Gladiolus segetum' per la forma de les fulles semblant a aquest estri (amb metàfora similar, lliri d'espases, espasa, espaseta, espadella, espadola [Masclans]; mall. claviol, modificació vulgar de gladiol, dim. de gladi 'espasa'). L'araucària es diu popularment arbre de pisos, per la direcció de les seves branques. De vegades s'ha de recórrer a la llengua antiga perquè cobri transparència la imatge: carabasseta de rabequet, per la comparació de l'euforbiàcia amb un rabequet, instrument antic que era un violí de tres cordes.

Pel que fa a l'àrea geogràfica de procedència, tenim les figues melenquines $o$ figa mèlica, que eren les figues procedents de Màlica, nom antic de Màlaga (Veny, 1988), i les burjassot o bordisssot, del poble valencià de Burjassot (Veny, 1981). Alacantines són les figues originàries d'Alacant (nom modificat en alagantines, galantines, cantines), napolitanes o politanes, les de Nàpols, argelines, les d'Alger (homonimitzades en angelines) (Rosselló et al., 1994). És ben transparent el mallorquí figues de l'Empordà.

La relació amb una habitud dels animals o dels humans pròpia de la planta també és productiva: herba capsotera, perquè al Maestrat «el niu del capsot es troba sempre agençat amb brins d'aquesta herba benefactora»; igualment herba capsigrallera, de capsigrall; o herba capsigranyera, de capsigrany (Masclans, 1981: 12).

La propietat curativa també té capacitat denominativa: la milfulles (Achillea millefolium) és coneguda com a herba de talls, $h$. de ferides o $h$. de tos (Masclans, 1981: 16). Però de vegades la deducció d'aquestes propietats terapèutiques està en relació amb el signe exterior de la planta (forma, color, lloc on creix, etc.): la forma trilobada de les fulles de la Anemone hepatica i el seu color vermellós són l'origen dels noms populars herba fetgera, fetgera o herba del fetge, que indiquen el poder curatiu de les malalties hepàtiques (Font i Quer, 1982: XXIV). En aquest cas es passa del nom a la virtut.

Molt sovint la transparència és clara i el mateix parlant en té consciència: ensopeguera, Limonium delicatum, per la facilitat amb què s'ensopega amb aquesta planta: «t'hi entrebanques abans d'haver-la vista» deia un pastor (Masclans, 1981: 10) (l'etimologia és un derivat d'ensopegar i aquest, de cep, encepegar).

$\mathrm{Cal}$ tenir en compte també les referències culturals, siguin religioses: blat del diable, heura del diable, figuera d'infern; siguin ètniques: carabassa morisca, tassa de jueu. I també les que són producte de la ironia: coixí de sogra 'cactus'. $\mathrm{O}$ referències religioses: pel temps de la collita herba de sant Joan 'espernallac, Santolina chamaecyparissus'; o un mot o expressió llatina, paternostera 'bufera, Withania frutescens'.

Així com en els noms de minerals el nom del descobridor a voltes s'ha incorporat al terme (per exemple, dawsonita), en el cas de la botànica també es dóna 
aquest procediment: així, begònia va ser creat pel botànic de Lluís XIV, Ch. Plumier (segle XVII), en honor de Michel Bégon, botànic intendent general de Sant Domingo; i magnòlia, en honor de Pierre Magnol, professor a la Universitat de Montpeller (DHLF; Climent-Zurriaga: 23-24). En tot cas, ha transcendit al nom científic, com Nicotiana tabacum i d'aquí el francès nicotine (traspassat al català nicotina), dedicada a Jean Nicot, embaixador francès a Portugal, i que l'introduí a França (Bonafè, IV: 90); o el plantatge de Bellardi 'plantago Bellardii' dedicat a aquest botànic italià (ibídem, 144); recordem que Miquel de Garganta (19031988), col-laborador de P. Fabra, en el seu exili colombià va descobrir noves espècies botàniques, on apareix el seu nom (Culcitium Gargantanum, Oreopanax Gargantae) (GEC); més interessant és per a nosaltres l'estèvia (Stevia rebaudiana) que el botànic Josep Antoni Cavanilles va crear dedicant la planta, originària d'Amèrica del Sud, al metge i naturalista també valencià, del Maestrat, Pere Jaume Esteve, amb el cognom llatinitzat, Petri Jacobi Stevii, com feia ell mateix signant els seus treballs (Piqueras, 2013).

\section{Homonímia i etimologia popular, impulsos renovadors del lèxic}

Gilliéron, fundador de la geolingüística, deia que un dels objectius de la llengua és la claredat en la comunicació i que l'homonímia n'és un obstacle que fa modificar els elements que l'afecten: POPULUS, PULLUS i PEDUCULUs han coincidit en poll en gran part del català: d'aquí que el poll botànic s'hagi modificat en arbre poll, pollanc, pollancre, o hagi estat substituït pel mot castellà, també passat a l'aragonès (ALEANR, III, mapa 399), xop, substitució afavorida per la comercialització a Catalunya de la fusta d'aquest arbre. ${ }^{2}$

Un altre motor de renovació lèxica en el parlar col-loquial, exposat per Gilliéron, és el que se n'ha dit etimologia popular, relacionada en l'anàlisi constant que el parlant fa de la seva llengua: així l'escabiosa, Scabiosa sp. omn. (ß SCABIOSA, de SCABIES 'sarna') s'ha transformat en escabeiosa, escabellosa, escopiosa. I la centaura (Centaurium erytraea), en santa Ana i fins santa Aura, introduint així un nom inexistent en el santoral cristià; i el seu sinònim, lleteresa, en llet de Santa Teresa, o de Santa Tresa. Igualment eucaliptus $\rightarrow$ carlitus, entre altres; maneula, Cynoglossum latifolium (< besneula), en manuela; etc. S. Gili Gaya (1918) va recollir bons exemples d'etimologies populars d'espècies botàniques.

\section{El repte de l'etimologia}

Des de la fundació de la filologia romànica, els estudiosos s'han ocupat de l'etimologia. Recordem que una de les obres cabdals de l'etimologia és l'Etymologisches Wörterbuch der romanischen Sprachen (EWRS), de Friedrich Diez, completat després pel Romanisches Etymologisches Wörterbuch (REW), de Meyer-Lübke, i encara pel Französisches Etymologisches Wörterbuch (FEW),

2. Guiter (1956) es va ocupar d'aquesta homonímia pel que fa al rossellonès. 
de W. von Wartburg. No oblidem la quantitat de diccionaris específics de cada llengua romànica, com, en el cas del català, el DCVB, d'Alcover i Moll i, sobretot, el DECat, de Coromines, a més de nombroses monografies que aborden etimologies concretes. Tots aquests treballs han fet possibles les respectives gramàtiques històriques i històries de la llengua del conjunt romànic i de cadascuna de les llengües romàniques. Hi ha tanta feina feta que l'etimologista actual es queda amb els ossos, amb les etimologies de mots desconeguts o que es resisteixen, incertes, dubtoses o totalment obscures. El que és important, com hem dit, és no limitar-se a establir l'etimologia d'una manera esquemàtica $\mathrm{B}<\mathrm{A}$, sinó de donar a conèixer la motivació del canvi semàntic, a més d'explicar-ne l'evolució formal: $\mathrm{A}>\mathrm{B}>\mathrm{b}_{1}>\mathrm{b}_{2}>\mathrm{b}_{3} \ldots$

\section{Dues noves etimologies: jovenal i panicrost}

Voldria ara exposar dos casos, explorats fins ara defectuosament, però que, gràcies a la copiositat de formes del corpus de plantes o de les referències metalingüístiques recollides a l'ALDC, cobren nova llum: jovenal i panicrost.

De la planta jovenal, Verbascum thapsus, el DCVB diu:

//1. adj. ant. Jovenil. «Oh tu, fembra juvenal, pus movible est que no los vents» (Scachs 106). // Planta Verbascum thapsus (Terra Alta, ap. Masclans Pl. 139); cast. gordolobo (V. blenera)

Etim.: del llatí IUVEnALE, mat. sig. 1. [derivat de JUVENis].

\section{I el DECat:}

Jovenal (s. Xv), dins l'article jove, la qual cosa vol dir que el considera un derivat de jove [s. XV es refereix a la data de la font Scachs, citada pel DCVB, que el considera derivat del llat. JUVENALE]

Si considerem les variants que ens ofereix el NP, sota dues espècies o un genèric (entrades capellans i blenera):

Verbascum lychnitis: jovenal, santjoans, jovanal, sant joans.

Verbascum thapsus: jovenal, santjoanal, santjoanals, joanal.

Verbascum L.: jovenal, herba de Sant Joan, santjoans, vares de Sant Joan.

crec que podem deduir que el nom té a veure amb sant Joan, per l'època de la floració, ${ }^{3}$ amb el derivat santjoanal, amb el sufix -al relatiu al temps (com primaveral, tardoral, hivernal), la reducció a joanal i la inserció d'una -v- antihiàtica, com ha passat en l'antropònim Jovany, Jubany i potser Juvanet, si és diminutiu de Juanet (o Joanet). ${ }^{4}$ Conclusió: el mot no té res a veure amb jove ni té per ètim

3. Vegeu semblantment per a la 'margarida' santjoans loc. 30, santxuanera loc. 99; flors de Sant Joan loc. 57, 114 i 123 (ALDC, 1091).

4. Moll (1982) interpreta el cognom com una grafia dialectal de jovenet, diminutiu de jove. 
el llatí juvenale, sinó que és un derivat de (Sant) Joan per l'època de floració de la planta. En consequiència, la forma ortogràfica hauria de ser jovanal i no jovenal, com posa el DIEC.

Panigroc (Anacyclus clavatus) és el mot normatiu acollit pel DG 1932 al qual el DIEC1 va afegir panicor.

Quant a l'etimologia, aquesta manca en el DCVB, que afegeix un panicort corresponent a l'espècie Anthemis arvensis, heretat de Masclans, que localitza a la Terra Alta (i que l'ALDC ha recollit amb la mateixa variant, panicort).

En canvi, el DECat fa malabarismes per a trobar una solució al problema etimològic:

Panicola i panicort semblen deguts a una alteració de panical (ESPONA), potser per contaminació de col (i potser no sense intervenció de formes com coleta 'Silene inflata', DECH II, 150.8, cf. encara herba-col, QUALLAR i alguna forma mossàrab o dialectal de CALÇ I, II); en tot cas deu haver-hi comunitat d'origen entre panicort i panigroc (DFa i AlcM) (cf. però joligroc a JULIVERT) i és evident que amb panical va card paniguer (Sopeira) (DECat, VI, 226a, 28-37).

Panigroc (?), però potser més aviat cal pensar en algun encreuament o combinació de panís amb groc o amb joligroc (JULL, LLIRI), o bé amb panical (espinar-cards) (DECat, VI, 154b, 33-36, s.v. pa).

El que és evident, com demostrarem, és que els mots no tenen res a veure amb el panís, ni amb el panical (<espinacal), ni amb la col, ni amb la calç ni amb el julivert i, menys encara, amb un mot del mossàrab, una capa evanescent de la llengua de la qual la moderna lingüística diacrònica elimina elements que s'hi havien atribuït. L'única aproximació és que el mot pertany al camp derivatiu de pa i que s'ha realitzat una homonimització amb groc.

El NP aporta aquesta documentació (prescindim de la referència a les fonts):

Anacyclus clavatus: panicors pl., panigroc ver, panigrog.

Anacyclus valentinus: panigroc, panigroc valencià.

La informació complementària de l'ALDC (V, 1091. La margarida) porta:

panicrostes loc. 67 , panicroc «més xiqueta que la margarida»loc. 113; panicrostos loc. $111 ; 5$ panicort loc. $128^{6}$

I bé, el desllorigador es troba en la cultura popular, en l'observació metalingüística d'un dels informants de l'ALDC (V, 1091, loc. 67) corresponent a la localitat de Sant Pere de Ribes, el qual, referint-se a la 'margarida silvestre', diu: «en diuen panicrostes perquè és una herba molt dolenta, i té aquest nom perquè, quan se posa amb un camp, diu: No colliràs ni pa ni crostes.»

5. Masclans recull panicrost a Calladrons (Baixa Ribagorça) per a Anthemis arvensis 'camamilla borda'.

6. Masclans recull panicor a Almatret (Segrià) per a Anthemis arvensis 'camamilla borda'. 
Les anàlisis metalingüístiques dels parlants sovint responen a la realitat i es converteixen en interpretacions etimològiques: així, un informant de Santanyí (Mallorca), a propòsit dels ruscos, deia: «se trobaran amb so nom que les diven caseres, com que són casetes, heu entén?, i noltros deim caieres i no sé per què» (vegeu Veny, 1992: 61).

En el cas concret que ens ocupa, el punt de partida és «(ni) pa ni crostes», des del quals s'han desprès:

panicrostos $(\mathrm{m}.) \rightarrow *$ panicrost $($ singular $) \rightarrow *$ panicroc (a partir del pl. *panicrots) $\rightarrow$ panigroc (per homonimització semàntica, car la flor és groga), $\rightarrow$ *panicorc $\rightarrow$ panicort (per metàtesi i equivalència acústica $-k=-t$, com els dialectals $c a ̀ v e c$ / càvet, ràvec/ràvet, pioc/piot 'galldindi', tàvec/tàvet, etc. (ALDC, pàssim).

\section{Estructura morfosintàctica}

Des del punt de vista de la formació sintagmàtica dels mots, tenim un exemple original — potser únic- de relació copulativa amb ni, amb l'esquema $X$ ni $Y$. I aquest cas ens acosta a l'altre tipus, ja estudiat (Cabré-Rigau, 1986: 139-140), $X$ i Y, exemplificat amb casos com plats-i-olles, vetesifils, capimoca i allioli, però que el lèxic botànic del NP permet enriquir amb moltes altres unitats:

- pare i fill, pares i fills 'capcetes, gravit, sarronets de pastor'.

- potes i manetes 'cantagallets', patimanetes Lonicera etrusca.

- sogra i nora 'amor de fadrí' Salvia microphylla Himb., Bonpl. et Kunth; sogres i nores 'balsamina' Impatiens balsamina L., 'cucut' Primula elatior.

A propòsit d'aquest nom Verdaguer ens explica la seva motivació: «bé li escau. Fa dues floretes girades en sentit oposat, com si es donessin l'esquena ... i tenen cert aire de voler fugir l'una de l'altra» (ap. Veny, 2006).

- fadrins i fadrines 'estrela de flor blava' Aster sedifolius L.

- pa i vi 'agrella' Oxalis debilis, 'pa de cucut de bosc', 'agrelleta' Riuex acetosella L. subsp. angiocarpus; pa i tu vi 'agrella' Oxalis debilis.

- pa i peixet 'borratja' Borrago officinalis L.; 'flor d'avellana' Oxalis pes-caprae L.

- fel i vinagre 'flor d'avellana' Oxalis pes-caprae L.

Un altre tipus morfolèxic és el tautològic $\mathrm{X}+\mathrm{X}$, que trobem repetidament en la flora algueresa:

- moc-moc 'borratja, Borago officinalis' (pròpiament 'moc' per la seva qualitat mucil-laginosa).

- mussi-mussi 'cua de llebre, cua de ca; Lagurus ovatus'. Repetició de la manera de cridar el gat (la gata, en alguerès), que suposa una anterior hipotètica *cua de mussi, reduïda a mussi-mussi (vegeu el men. moixos per a la mateixa planta).

- cuca-cuca 'cua de rata; Phleum pratense'. Potser postverbal de cucar (< it. cuccare 'picar, picotejar')

- víltiga-víltiga 'ortiga gran, ortiga petita; Urtica dioica, Urtica urens', del log. bértiga (< llat. PERTIGA 'vara, branqueta'). 
- gard pixa-pixa 'cardot picnocèfal, card gallofer; Carduus pycnocephalus'. Adaptació del sard galdu piscia-piscia, dit així per les seves propietats diurètiques.

Els cinc mots són estudiats per Caria (2001) i acollits en Sanna (1988). Es tracta d'un sistema de superlatiu, heretat del sard, i que, dins el conjunt del català, confereix personalitat a l'alguerès.

\section{Botànica i normativa}

En relació amb la normativa, cal subratllar la utilitat del NP per tal de constatar, en conjunt, quins són els termes botànics incorporats al DIEC, reunits en sinonímia, i quins no ho han estat. Sorprèn l'alt nombre de sinònims —o, millor, geosinònims - que ha admès el DIEC: el passacamins (Polygonum aviculare) en té 9, com el canyís (Phragmytes australe), l'espernallac (Santolina cyparissus), el galzeran (Ruscus aculeatus) i l'herba blenera, amb 12 variants; l'herbacol, amb 14; conillets (Antirrhynum majus), amb 15 variants; però altres només presenten una variant normativa, pèl de farigola (Cuscuta epithymum), enfront de 46 variants dialectals. Tot això confirma l'obertura estàndard cap a les variants diatòpiques, iniciada per Fabra i ampliada en bona hora per la Secció Filològica de l'Institut. Així, de 3 entrades del DG 1932 per a 'conillets' (Antirrhynum majus), boca de conill, gatolins i vedells, s'ha passat a 15 en el DIEC. No oblidem que Fabra comptava amb la col-laboració de naturalistes com Miquel de Garganta (19031988) per a la selecció d'espècies botàniques i l'aplicació del seu nom correcte (vegeu Riera-Vallès, 1991).

\section{Botànica i poesia}

Finalment, no podem oblidar la relació de la fitonímia amb la poesia. Verdaguer dedica tot un llibre, Brins d'espígol, a la flora que inspirava els seus meravellosos versos. Més recentment, Maria del Mar Bonet canta un poema de Josep M. Llompart, Camí florit, ${ }^{7}$ format solament per noms de plantes, 38 fitònims de pura raça catalana, sense cap interferència:

\author{
Llevamà, card, fonollassa, \\ rosella, cascall, lletsó, \\ vinagrella, corritjola, \\ ginesta, aritja, fonoll, \\ passionera, cugula, \\ mareselva, safrà bord, \\ floravia, canyaferla, \\ baladre, argelaga, albó,
}

\author{
falguera, olivarda, estepa, \\ clavell de moro, coscoll, \\ heura, contell, englantina, \\ vidalba, murtra, maimó, \\ cama-roja, campaneta, \\ ravenissa, bruc, guixó, \\ (i en l'aire color de vauma \\ l'esgarrifança d'un poll).
}

7. Que forma part del llibre de poemes Jerusalem (1990). 
D'altra banda, les múltiples espècies de papallones estaven mancades de noms populars. El TERMCAT ha procedit a una adaptació de noms científics de les diürnes i molts d'ells procedeixen del nom de la planta nutrícia, que ha donat origen a una nomenclatura atractiva i fins i tot poètica. David Jou, físic i poeta, n'ha fet poesia sigui simplement ajuntant els noms, com en aquesta estrofa:

Murri de la pimpinella, damer de la valeriana, perlada de la filipèndula, bruna de secà, vellutada del salze, lleonada de matollar, verdeta de l'ull blanc, muntanyesa tardana

sigui introduint els mots en versos d'una sonoritat plaent, d'una gran bellesa:

Nimfa de bosc, damer de la centàurea, brocat de l'escabiosa, blaveta de l'estràgal, capgròs del malrubí, faune de ziga-zaga...

Aquests noms que inviten a dansar per l'aire, al plaer del vol, al repòs de la pausa, que juguen i enlluernen, que brillen i proclamen color, bellesa, vida, lluminositat i gràcia!

Aquests noms que evoquen ingravidesa, calma, vols de flor en flor, regals a la mirada, luxes de lepidòpter, orfebreria alada, que seductors són!: diuen un món, i canten.

Margenera comuna, papallona zebrada, daurat de punta negra, blaveta de ratlla blanca, coure tornassolat, turquesa mediterrània...

Noms de papallones al cel de la paraula.

\section{Conclusions}

En aquest viatge fitonímic hem subratllat els camins etimològics i motivacionals de certes plantes $\mathrm{i}$ els factors de canvi lingüístic, hem desvelat l'origen dels noms de dues plantes, el jovenal i el panigroc, hem donat a conèixer nous models sintagmàtics de la flora i hem il-lustrat l'abundor de geosinònims incorporats a l'estàndard.

\section{Referències bibliogràfiques}

ALDC = Veny, J.; Pons, L. (2008 i 2010). Atles Lingüístic del Domini Català, IV i V. Barcelona: Institut d'Estudis Catalans. 
ALEANR = Alvar, M. (1979). Atlas lingüístico y etnográfico de Aragón, Navarra y Rioja. Zaragoza, $12 \mathrm{v}$.

Bigas, M.; Milian, M. (1996). Anàlisi morfolèxica dels noms de plantes. Barcelona: Institut d'Estudis Catalans [Biblioteca Filològica, XXXI].

Bonafè, F. (1077). Flora de Mallorca. Mallorca: Moll. 4 vol.

CABré, M. T.; Rigau, G. (1986). Lexicologia i semàntica. Barcelona: Enciclopèdia Catalana.

CAria, R. (2001). Le piante spontanee ad Alghero. Nomi. Proprietà. Usi. Etimologia. Alghero: Editrice Democratica Sarda.

Cavanilles, A. J. (1795). Observaciones sobre la historia natural, geografía, agricultura, población y frutos del reyno de Valencia. Madrid: Imprenta Real.

Climent, D.; Zurriaga, F. (2012). Herbari. Viure amb les plantes. València: Universitat de València / Jardí Botànic / Mètode.

DCVB = Alcover, A. M.; DE B. Moll, F. (1930-1962). Diccionari català-valencià-balear . Palma de Mallorca, 10 vol.

DG = Fabra, Pompeu (1932). Diccionari general de la llengua catalana. Barcelona: Llibreria Catalònia.

DHLF $=$ Rey, A. (dir.) (1994). Dictionnaire historique de la langue française. París: Dictionnaires Le Robert.

GEC = Gran Enciclopèdia Catalana, VII. Barcelona: Enciclopèdia Catalana, 1974.

Gill GayA, S. (1918). «Casos de etimología popular en nombres de plantas». Anuari de l'Oficina Romànica de Lingüística i Literatura, 1, 241-246.

Guiter, H. (1956). «Un cas d'homonymie triple: catalan poll». Revue des Langues Romanes, 72, 171-195.

IoRDAN, I. (1967). Lingüística románica. Evolución - corrientes - métodos. Reelaboración parcial y notas de Manuel Alvar. Madrid: Ediciones Alcalá.

Masclans, F. (1981). Els noms de les plantes als Països Catalans, 2a ed. Granollers/Barcelona: Montblanc-Martin.

Moll, F. de B. (1982). Els llinages catalans (Catalunya, País Valencià, Illes Balears). Assaig de divulgació científica. Mallorca: Moll.

NP= Vallès, J. (dir.); Veny, J.; Vigo, J.; Bonet, M. A.; Julià, M. A.; Villlalonga, J. C. (2014). Noms de plantes. Corpus de fitonímia catalana. Barcelona: Departament de Cultura (Generalitat de Catalunya) / TERMCAT.

PiQueras, M. (2013). «L'estèvia: planta forastera, nom nostrat». Ara, 24 març 2013.

Riera, C.; Vallès, J. (ed.) (1991). Pompeu Fabra, Pius Font i Quer i Miquel de Garganta. Un epistolari fonamental per a la lexicografia catalana (1928-1953). Barcelona: Institut d'Estudis Catalans.

Rosselló, J.; RAllo, J.; SACARÈs, J. (1994). Les figueres mallorquines. Mallorca: Gràfiques Miramar.

VenY, J. (1980). «Sobre els occitanismes del rossellonès». A: Bruguera, J.; Massot I Muntaner, J. (ed.), Actes del V Col-loqui Internacional de Llengua i Literatura Catalanes (Andorra 1979), Barcelona, 441-494.

— (1981). «De re ficaria: cat. bordissots i paratjals». Affar, I, 37-46.

—(1988). «De Màlica a les figues melenquines». A: Studia in honorem Prof. Martí de Riquer, vol. 3. Barcelona: Quaderns Crema, 177-194.

— (1992). «Actituds metalingüístiques en textos dialectals». A: Col-loqui sobre les fonts orals (Monestir de la Real, Palma, 12-15 abril 1982). Universitat de les Illes Balears, 57-61.

— (2006). «Llengua i territori en l'obra de Verdaguer», Anuari Verdaguer [Actes del Colloqui Internacional sobre Verdaguer: llengua, retòrica i poètica], 14, 17-55. 
- (2013). «Circulacions lingüístiques en la Romània». A: Casanova, E.; Calvo, C. (ed.), Actes del 26è Congrés de Lingüística i Filologia Romàniques (València, 6-11 setembre de 2010). Berlín: W. de Gruyter, 495-511.

Verdaguer, J. (1981). Brins d'espígol. Primera edició preparada per A.-J. Soberanas. Tarragona: Institut d'Estudis Tarraconenses Ramon Berenguer IV.

Villalonga, J. C. (2010). «Un mot fantasma, poltre d'eruga». Estudis Romànics, 32, 363-367. 